\title{
Re: Hand-assisted Laparoscopic Retroperitoneal Donor Nephrectomy: A Single-institution Experience of Over 500 Cases-operative Technique and Clinical Outcomes
}

\author{
Kumar S, Witt RG, Tullius SG, Malek SK
}

Brigham and Women's Hospital, Clinic of Surgery, Boston, MA, USA

Clin Transplant 2018;32:e13261. doi: 10.1111/ctr.13261. Epub 2018 May 12.

\section{EDITORIAL COMMENT}

Laparoscopic living donor nephrectomy is the gold standard for performing live donor nephrectomies, however, there is no consensus as to the best variation of the technique. In this single center retrospective study, the authors have described their hand-assisted laparoscopic retroperitoneal donor nephrectomy technique and outcomes in 507 consecutive donors over a 14-year period. The authors have completed their procedures with low morbidity and short operative times, and with safe removal of either the right (33.7\%) or left kidney (66.7\%), regardless of vascular anatomy with minimal warm ischemia time, without the need for conversion to open procedure. Lack of venous thrombosis in right donor nephrectomies and only one incisional hernia development are of importance in contradiction to previously reported series. However, the retrospective nonrandomized nature of the study prevents making rigid conclusions.

Yarkın Kamil Yakupoğlu, MD 